\title{
The in situ Analysis of Interfacial Reactions between Electrode and Organic Electrolytes II. Electrodeposition of Lithium at $\mathrm{Cu}$ Electrode
}

\author{
Ken-ichi MORIGAKI*, Akiyoshi MORITA and Akira OHTA
}

Received September 1, 1997 ; Accepted May 13, 1998

\begin{abstract}
We investigated the effects of electrolytes on the electrodeposition of lithium at $\mathrm{Cu}$ electrode using in situ FTIR and AFM measurements. The electrolyte solutions used were EC+DMC and EC+DEC each including $1 \mathrm{~mol} / \mathrm{dm}^{3} \mathrm{LiPF}_{6}$. The AFM observation showed that the electrodeposition of lithium occurred as a formation of small particles about $0.5 \mu \mathrm{m}$ in size and several particles combined and grew up larger than $1 \mu \mathrm{m}$ at $\mathrm{Cu}$ electrodes. As the effects of DEC, the particle size of deposited lithium grew larger than in EC+DMC system, especially at a charging current density of $1 \mathrm{~mA} / \mathrm{cm}^{2}$. The in situ FTIR spectroscopy showed the difference in the surface reaction with deposited lithium in EC+DMC and in EC+DEC system.
\end{abstract}

\section{INTRODUCTION}

Recently, the development of the portable electronic appliances requires the rechargeable batteries with smaller size, lighter weight and higher energy density. Therefore, it is expected that rechargeable lithium batteries using lithium metal anode will be better performance, such as higher energy density, than lithium-ion batteries. The difficulty of the lithium metal anode is the low efficiency of charge-discharge cycles depending on that the morphology of deposited lithium is not smooth but dendritic. It is well known that the electrolytes effect on the cycling efficiency of lithium and the morphology of deposited lithium, so the interfacial reaction between lithium and electrolytes is the one of the most important factors in rechargeable lithium battery system. But the amount of these products is very small amount, and these products generally form very thin layer and react with $\mathrm{H}_{2} \mathrm{O}, \mathrm{CO}_{2}$ and $\mathrm{O}_{2}$ which are atmospheric components. Since these products are very instable, it is necessary to conduct in situ analysis and experiments in the study of lithium batteries.

Fourier Transform Infrared(FTIR) spectroscopy is one of the useful method for in situ analysis of the interfacial reactions on the electrodes in organic electrolytes. Technology Laboratory, Matsushita Battery Industrial Co.,LTD., (1, Matsushita-cho, Moriguchi, Osaka 5708511, Japan)

Key Words: in situ analysis, FTIR, AFM, organic electrolyte.
Aurbach et. al., investigated the surface reactions of lithium in many organic electrolytes by in situ FTIR ${ }^{1 \sim 4)}$ Scanning Probe Microscopy(SPM) including Scanning Tunneling Microscopy(STM) and Atomic Force Microscopy(AFM) are also regarded as useful methods for in situ analysis. We have demonstrated AFM observation is a useful method for in situ analysis of the lithium surface and for the study of deposition in organic electrolytes. ${ }^{5,6)}$ Aurbach also investigated the topographic study of lithium cleposition at $\mathrm{Cu}$ electrode by AFM observation. ${ }^{7}$ )

In this report we demonstrated AFM observation and FTIR spectroscopy(the external reflectance mode, IRAS and $\operatorname{DMFTIR}^{8,9)}$ ) for in situ analysis of lithium electrodeposion and the interfacial reaction between organic electrolytes and lithium deposited on $\mathrm{Cu}$ electrode.

\section{EXPERIMENTAL}

Ethylene carbonate(EC), dimetyl carbonate(DMC), and diethyl carbonate(DEC) purchased from Mitsubishi Chemical and $\mathrm{LiPF}_{6}$ purchased from Stella Chemifa were used as received. The electrolytes used were EC+DMC (1:1 by volume) and EC+DEC(1:1 by volume) each containing $1 \mathrm{~mol} / \mathrm{dm}^{3} \mathrm{LiPF}_{6}$, and below $50 \mathrm{ppm}$ of water. FTIR experiments were performed on a Mattson RS-2 spectrometer as sarne as reported in our previous pepar. ${ }^{10)}$ 100 scans were conducted in each measurement, and the resolution was $2 \mathrm{~cm}^{-1}$. Reflection Adsorption Spectroscopy(IRAS) using p-polarized IR beam was performed as 
one method to investigate the reduction of electrolytes. The DMFTIR spectroscopy was performed as the other method using p-polarized and s-polarized IR beams modulated by photoelastic modulator(PEM-90,Hinds). The DMFTIR spectra data were sampled by the realtime sampling electronics(Mattson) the difference between ppolarized data and s-polarized data as a sample spectrum, and the sum of $\mathrm{p}$ - and s-polarized data as a reference. Consequently, the DMFTIR spectrum indicates the difference of the species between at the surface and in the bulk phase. The center frequency of DMFTIR was set at $1200 \mathrm{~cm}^{-1}$ in the present study. The spectroelectrochemical test cell for in situ FTIR and the electrochemical test cell for in situ AFM were the same as reported in our previous papers. ${ }^{6,10)}$ A cylindrical piece $(\phi 8 \mathrm{~mm})$ of copper(purity: $99.5 \%$ ) was used as a working electrode, and it was polished with fine alumina powders $(0.05 \mu \mathrm{m})$ to obtain a mirror surface. Lithium metal was used as a counter electrode and a reference electrode in the test cells. The in situ AFM measurements of $\mathrm{Cu}$ electrodes were performed on TMX-1000(Topometrix) as same as reported in our previous papers. ${ }^{5,6)}$ In the present study a FTIR spectro- meter and AFM system were placed in dry-air atmosphere maintained a dew point of lower than $-45^{\circ} \mathrm{C}$. The potentiostatic and galvanostatic polarization for the electrodeposition of lithium were performed by a potentio/galvanostat HA-301(Hokuto denko) and a function generator HB-104(Hokuto denko). The previous cathodic polarizations over $0 \mathrm{~V}$ vs. $\mathrm{Li} / \mathrm{Li}^{+}$were performed before the electrodeposition to distinguish the changes of deposition from the reduction of electrolytes. The in situ AFM observation was performed at open circuit voltage after the galvanostatic polarization, and the in situ FTIR measurement at the potentiostatic polarization was performed after the current was decreased under $20 \mu \mathrm{A}$. All experiments were performed at room temperature.

\section{RESULTS and DISCUSSION}

Figure 1 shows AFM images $(20 \times 20 \mu \mathrm{m}$ area) of the electrodeposition of lithium at $\mathrm{Cu}$ electrode by the constant current polarization(current density; $0.5 \mathrm{~mA} / \mathrm{cm}^{2}$ ) in $1 \mathrm{~mol} / \mathrm{dm}^{3} \mathrm{LiPF}_{6} / \mathrm{EC}+\mathrm{DEC}$. In the present study AFM images were treated by a leveling process and a modification of the irregular traces in the scanning. The

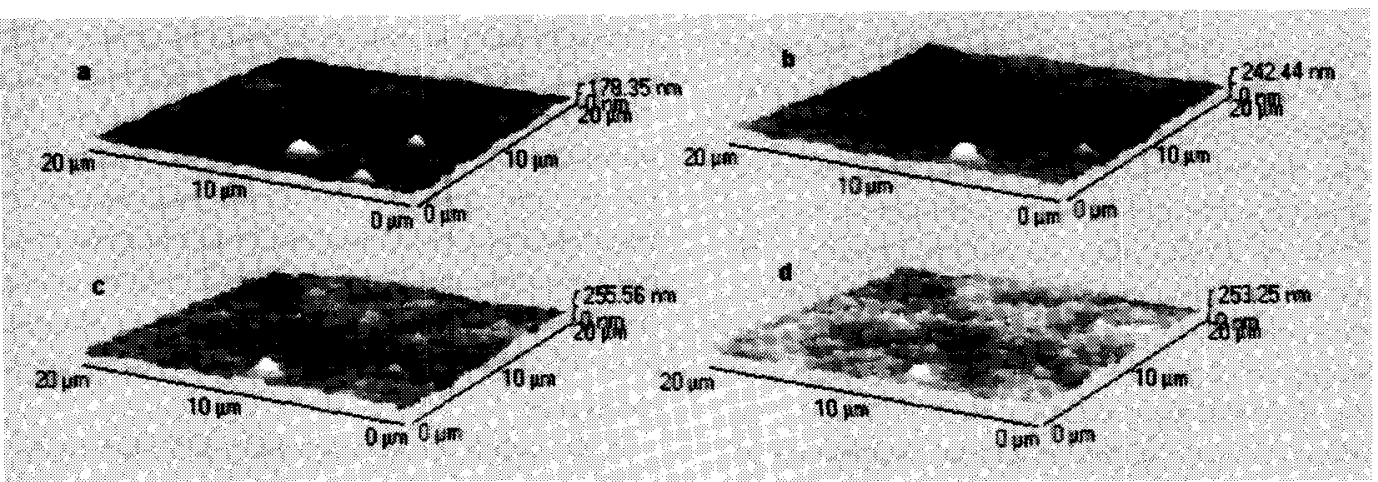

Fig. 1 AFM images of electrodeposited lithium on Cu electrode in $1 \mathrm{~mol} / \mathrm{dm}^{3}$ LiPF $6 / E C+D E C$. Current density; $0.5 \mathrm{~mA} / \mathrm{cm}^{2}$. a; before deposition, b; $0.03 \mathrm{C} / \mathrm{cm}^{2}, \mathrm{c} ; 0.18 \mathrm{c} / \mathrm{cm}^{2}, \mathrm{~d} ; 0.3 \mathrm{C} / \mathrm{cm}^{2}$.

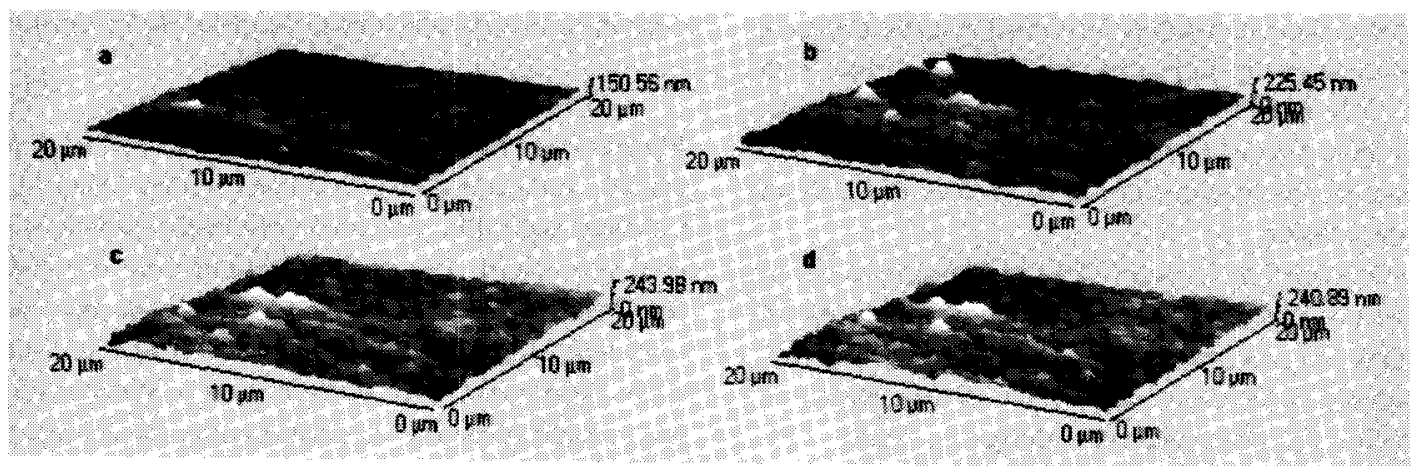

Fig. 2 AFM images of electrodeposited lithium on Cu electrode in $1 \mathrm{~mol} / \mathrm{dm}^{3} \mathrm{LiPF} / \mathrm{EC}+\mathrm{DEC}$. Current density; $2.0 \mathrm{~mA} \mathrm{~cm}^{2}$. a; before deposition, b; $0.03 \mathrm{C} / \mathrm{cm}^{2}, \mathrm{c} ; 0.18 \mathrm{C} / \mathrm{cm}^{2}, \mathrm{~d} ; 0.3 \mathrm{C} / \mathrm{cm}^{2}$. 
$\mathrm{Cu}$ electrode was polarized from $1 \mathrm{~V}$ to $0 \mathrm{~V}$ vs. $\mathrm{Li} / \mathrm{Li}^{+}$once before deposition to distinguish the morphological changes due to lithium deposition from the precipitation of reduction products of electrolytes(LiPF6 and/or solvents). The AFM image at $0.2 \mathrm{~V}$ vs. $\mathrm{Li} / \mathrm{Li}^{+}$(Fig. la) was slightly changed from the fresh surface by the reduction of electrolytes. The morphological changes due to lithium deposition(Fig. 1d) were observed as a formation of small particles $(300 \sim 600 \mathrm{~nm}$ in size) at the whole observing area. It seem that the topography of $\mathrm{Cu}$ electrode did not effect so much on the lithium deposition at this condition.

The morphology of electrodeposited lithium at high current density $\left(2.0 \mathrm{~mA} / \mathrm{cm}^{2}\right)$ in $1 \mathrm{~mol} / \mathrm{dm}^{3} \mathrm{LiPF}_{6} / \mathrm{EC}+$ DEC are shown in Fig. 2. The AFM image of deposition at initial stage(Fig.2b) showed the unevenness of deposition (the left side of Fig. $2 \mathrm{~b}$ and $2 \mathrm{c}$ ), and it seemed that the topography of the electrode surface effected on the deposition. It was clearly shown that the morphology and the roughness of deposition were affected by the current density of deposition from a comparison of the AFM images of Fig.1d and Fig.2d. But the particle size of lithium deposited was not influenced by the current density at the initial stage(amount of the deposition was under $0.18 \mathrm{C} / \mathrm{cm}^{2}$ ).

Figure 3 shows AFM images $(5 \times 5 \mu \mathrm{m}$ range) of electrodeposited lithium at various current density $(0.2 \sim$ $2 \mathrm{~mA} / \mathrm{cm}^{2}$ ) in $1 \mathrm{~mol} / \mathrm{dm}^{3} \mathrm{LiPF}_{6} / \mathrm{EC}+\mathrm{DMC}$. The morphology of deposition were observed as formations of small particles. Typical particle size of deposited lithium was $300 \mathrm{~nm}$ in length and $50 \mathrm{~nm}$ in height, and the largest one was $700 \mathrm{~nm}$ in length and $140 \mathrm{~nm}$ in height at the low current density of $0.2 \mathrm{~mA} / \mathrm{cm}^{2}$ (Fig. $3 \mathrm{~d}$ ). In case of current density was $2.0 \mathrm{~mA} / \mathrm{cm}^{2}$, typical particle size was $500 \mathrm{~nm}$ in length and $40 \mathrm{~nm}$ in height, and the largest one was $800 \mathrm{~nm}$ in length and $100 \mathrm{~nm}$ in height(Fig. 3a). Although large morphological changes were not observed at the initial stage(amount of the deposition was under 0.18 $\mathrm{C} / \mathrm{cm}^{2}$ ), as the growth of deposition was proceed, some gatherings of several small particles were observed at each conditions. While many small particles of deposited lithium were separately appeared at lower current density(Fig. $3 \mathrm{c}$ and $3 \mathrm{~d}$ ), the many gatherings of small particles were observed at high current density of $2.0 \mathrm{~mA} / \mathrm{cm}^{2}$ (Fig.3a). It seems that these gatherings of particles will grow as the nuclei of dendritic growth. Consequently, we think that the current density of deposition affects on this secondary growth of deposited lithium and which is related to the dendritic growth.

Figure 4 compares the morphology of electrodeposited lithium in $1 \mathrm{~mol} / \mathrm{dm}^{3} \mathrm{LiPF}_{6} / \mathrm{EC}+\mathrm{DMC}$ and in $1 \mathrm{~mol} / \mathrm{dm}^{3}$ $\mathrm{LiPF}_{6} / \mathrm{EC}+\mathrm{DEC}$. There were some difference in the AFM images of before deposition. The morphological change of the surface due to the reduction of electrolytes occurred at $0.2 \mathrm{~V}$ vs. $\mathrm{Li} / \mathrm{Li}^{+}$(Fig.4a and $4 \mathrm{~d}$ ), as a formation of small particles. The average size of raised particles in $\mathrm{EC}+\mathrm{DEC}$ was around $500 \mathrm{~nm}$, and it was larger than the particle (around $300 \mathrm{~nm}$ ) observed in EC+DMC. The roughness of $\mathrm{Cu}$ electrodes were almost the same level, such as average height and roughness parameter $\mathrm{Ra}$ were $49.18 \mathrm{~nm}$ and $11.62 \mathrm{~nm}$ in EC+DMC(Fig.4a), $52.71 \mathrm{~nm}$ and $8.91 \mathrm{~nm}$ in EC+DEC(Fig.4d). The AFM images of deposited lithium are shown in Fig. $4 \mathrm{~b}$ and $4 \mathrm{e}$ with Lateral Force Microscopy(LFM) images(Fig.4c and 4f). The LFM image reflects the bending and twisting of the cantilever when the cantilever moves on the surface of sample. The LFM image indicates the different friction force due to the various surface species, with the surface topography Therefore, the LFM image reflects the degree of the homogeneity and the uniformity of the surface species, and indicates the distinct surface topography. And the

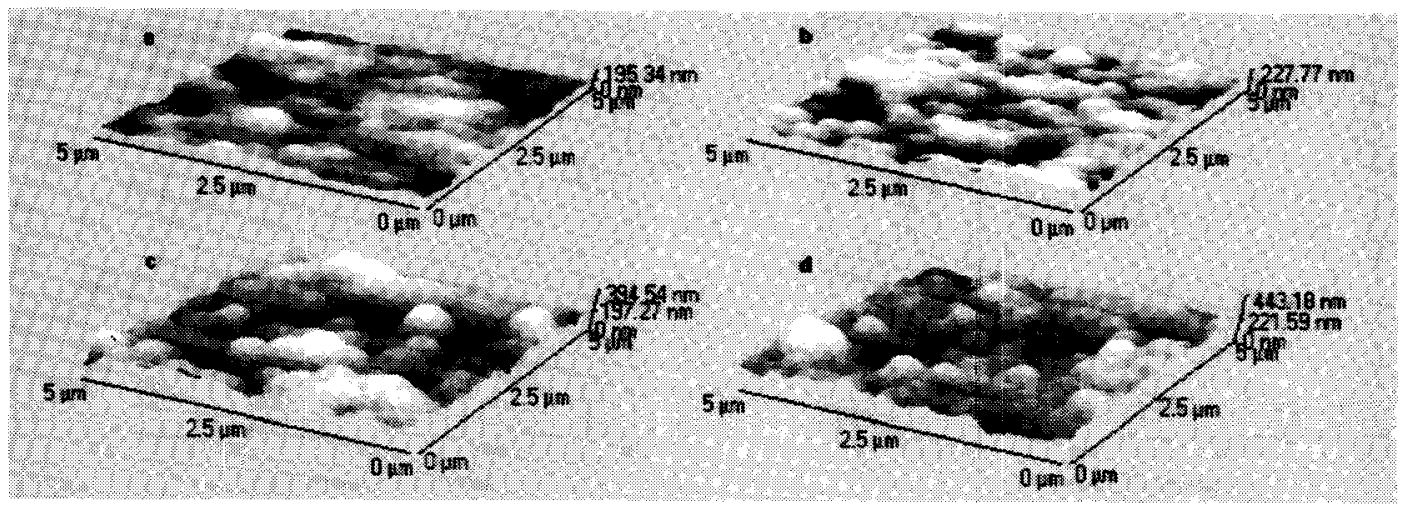

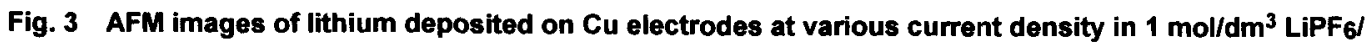
EC+DMC. a; $2.0 \mathrm{~mA} / \mathrm{cm}^{2}, b ; 1.0 \mathrm{~mA} / \mathrm{cm}^{2}, c ; 0.5 \mathrm{~mA} / \mathrm{cm}^{2}, d ; 0.2 \mathrm{~mA} / \mathrm{cm}^{2}$, amount of depositon; $0.3 \mathrm{C} / \mathrm{cm}^{2}$. 


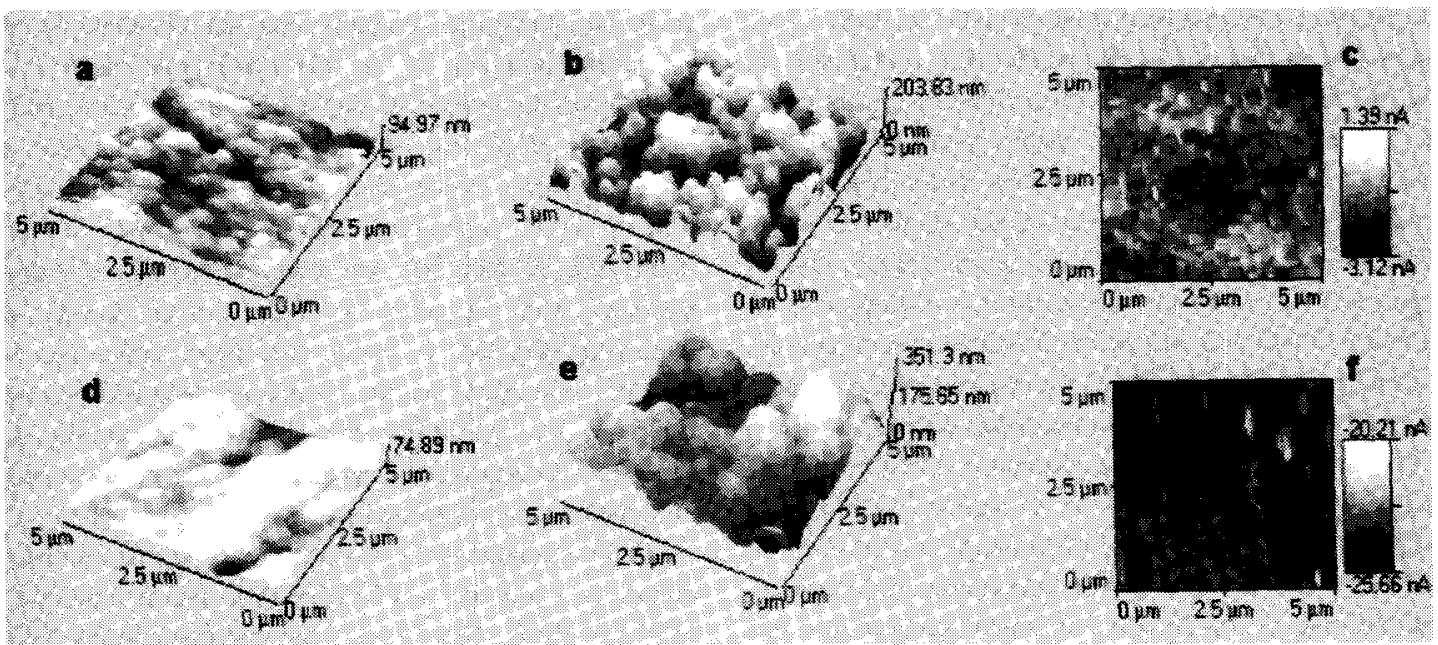

Fig. 4 Comparison of the morphology of lithium deposited on Cu electrodes in LiPF $6 / E C+D M C(a \sim c)$ and in LiPF $6 / E C+D E C(d \sim f)$. Current density; $1.0 \mathrm{~mA} / \mathrm{cm}^{2}$, a, d; before deposition(0.2V vs. $\left.\mathrm{Li}^{2} \mathrm{Li}^{+}\right), \mathrm{b} ; 0.18 \mathrm{C} / \mathrm{cm}^{2}$, c; LFM of $b$ in EC+DMC, e; $0.18 \mathrm{C} / \mathrm{cm}^{2}$, $f$; LFM of $e$ in EC+DEC.

LFM image can be obtained with the AFM image for the same scanning area. Typical particle of deposited lithium was $400 \mathrm{~nm}$ in length and $40 \mathrm{~nm}$ in height, and the size of a gathering consisted with several small particles was $1400 \mathrm{~nm}$ in length and $140 \mathrm{~nm}$ in height in EC+DMC. On the other hand in EC+DEC system, typical particle of deposited lithium was $800 \mathrm{~nm}$ in length and $60 \mathrm{~nm}$ in height, which was twice as large as that of in EC+DMC. The largest particle was $1200 \mathrm{~nm}$ in length and $170 \mathrm{~nm}$ in height, which was almost the same size as the gathering of particles in EC+DMC. These differences in the morphol-

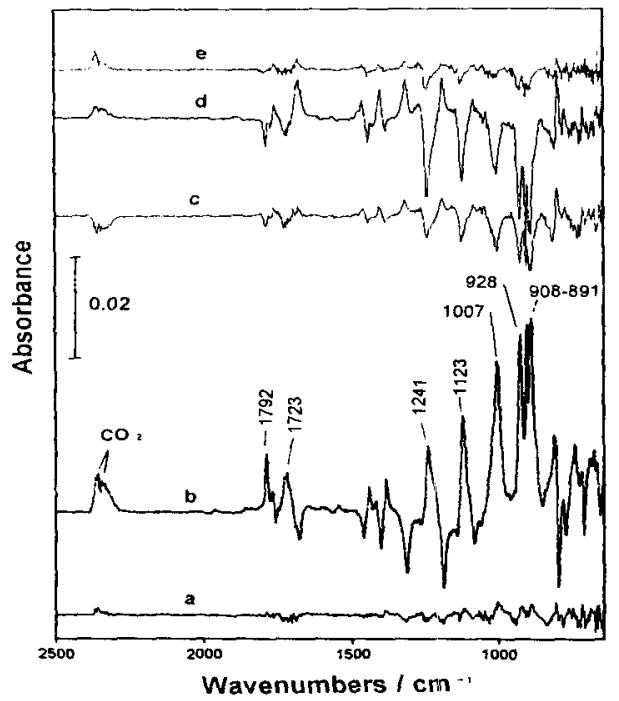

Fig. 5 IRAS spectra of $1 \mathrm{~mol} / \mathrm{dm}^{3}$ LilPF $6 / E C+D M C$ at

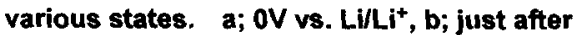
deposition, c; after $15 \mathrm{~min}, \mathrm{~d}$; $30 \mathrm{~min}$, e; $60 \mathrm{~min}$. ogy of deposited lithium between in EC+DMC and in $\mathrm{EC}+\mathrm{DEC}$ were remarkable appearance at the current density of $1.0 \mathrm{~mA} / \mathrm{cm}^{2}$.

We think that the difference in the growth mechanism of lithium deposition on $\mathrm{Cu}$ electrodes in $\mathrm{EC}+\mathrm{DEC}$ from in $\mathrm{EC}+\mathrm{DMC}$ was influenced by the reduction products of solvents and the behavior of products at the interface. Therefore, we examined in situ FTIR spectroscopy to analyze the interfacial reaction.

Figure 5 shows IRAS spectra of $1 \mathrm{~mol} / \mathrm{dm}^{3} \mathrm{LiPF}_{6} / \mathrm{EC}+$ DMC before and after deposition. The $\mathrm{Cu}$ working

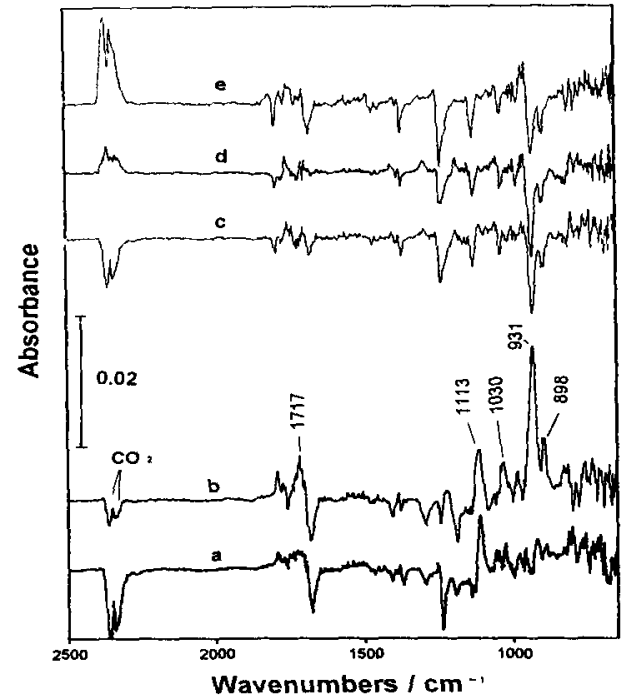

Fig. 6 IRAS spectra of $1 \mathrm{~mol} / \mathrm{dm}^{3} \mathrm{LiPF}_{6} / \mathrm{EC}+\mathrm{DEC}$ at various states. a; OV vs. $\mathrm{Li}^{2} \mathrm{Li}^{+}$, b; just after deposition, c; after $15 \mathrm{~min}$, d; $30 \mathrm{~min}$, e; $60 \mathrm{~min}$. 
electrode was cycled 3 times from $1 \mathrm{~V}$ to $0 \mathrm{~V}$ vs. $\mathrm{Li} / \mathrm{Li}^{+}$ before deposition. The lithium deposition with in situ FTIR measurement was performed by the constant voltage polarization at $-0.1 \mathrm{~V}$ vs $\mathrm{Li} / \mathrm{Li}^{+}$for 5 minutes. And then the $\mathrm{Cu}$ electrode was kept at the state of open circuit voltage for over 1 hour. The spectrum $5 \mathrm{a}$ (before deposition) was obtained at $0 \mathrm{~V}$ vs. $\mathrm{Li}^{2} \mathrm{Li}^{+}$by the interferogram at $0.5 \mathrm{~V}$ as a reference spectrum. The spectrum $5 \mathrm{~b}$ after deposition was obtained by the interferogram of $5 \mathrm{a}$ as a reference, and the spectra of $5 \mathrm{c} \sim \mathrm{e}$ were obtained by the interferogram of $5 b$ as a reference, respectively. The major increased peaks after deposition (5b) were triple peaks from 908 to $891 \mathrm{~cm}^{-1}$ and a peak at $928 \mathrm{~cm}^{-1}$, which seemed to be ascribed to the $\mathrm{C}-\mathrm{O}$ and $\mathrm{C}-\mathrm{C}$ stretching vibration of ether-compounds. The other increasing peaks were observed at 1792, 1723(uc-o), 1241,1123 and $1007 \mathrm{~cm}^{-1}$ at the spectrum $5 \mathrm{~b}$. The peaks at $1792\left(\mathrm{uC}_{\mathrm{C}} \mathrm{O}\right), 1241$ and $1123 \mathrm{~cm}^{-1}$ (Uc-o) will be due to $\mathrm{EC}$ which was replaced with reduced solvents, and the other peaks observed from 1100 to $800 \mathrm{~cm}^{-1}$ will be ascribed to ether-compounds which were the reduction products of EC and DMC. The doublet peaks(at 2360 and $2340 \mathrm{~cm}^{-1}$ ) assigned to $\mathrm{CO}_{2}$ were also increased at the spectrum $5 \mathrm{~b}$ and this increase indicated the decomposition of solvents. The spectra $5 \mathrm{c}$ and $5 \mathrm{~d}$ showed the decrease of the peaks increased at $5 \mathrm{~b}$, which were the reduction products of solvents. Therefore, it seemed that the dissoluble products, such as ether-compounds, were diffused from the interface to the bulk phase and the surface of deposited lithium was passivated with insoluble products.

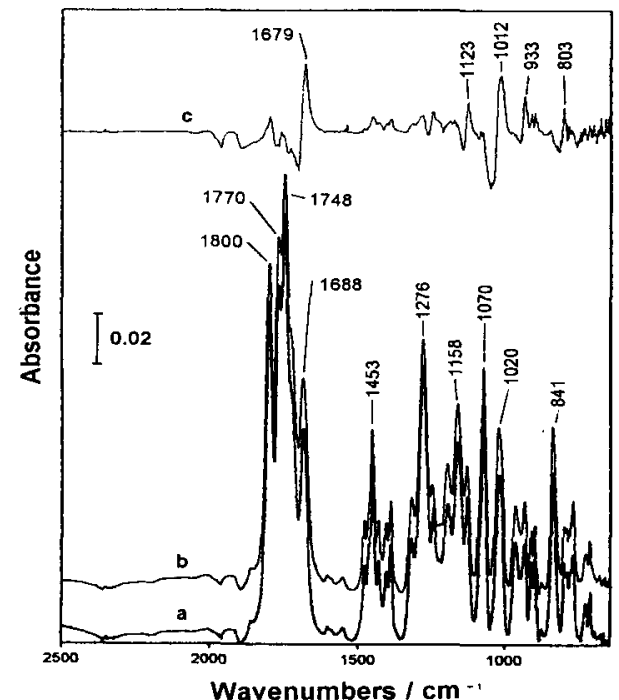

Fig. 7 Comparison of DMFTIR spectra of LiPF $6 / E C+$ DMC at OCV and after deposition. a; OCV(around $3 \mathrm{~V}$ ), b; after deposition, c; subtractive spectrum.
IRAS spectra of $1 \mathrm{~mol} / \mathrm{dm}^{3} \mathrm{LiPF}_{6} / \mathrm{EC}+\mathrm{DEC}$, as the same in Fig.5, are shown in Fig.6. The major increasing peak in the spectrum of the just after deposition(6b) was observed at $931 \mathrm{~cm}^{-1}$, which seemed to be ascribed to the C-O stretching vibration of ether-compounds. The other increasing peaks were observed at $1717\left(\mathrm{vC}_{\mathrm{C}} \mathrm{O}\right), 1113$, 1030 and $898 \mathrm{~cm}^{-1}$. These peaks except $1717 \mathrm{~cm}^{-1}$ would be ascribed to ether-compounds which were the reduction products of EC and DEC. The spectra obtained after deposition $(6 c \sim c)$ were almost the same, except the peaks of $\mathrm{CO}_{2}$. The increase of $\mathrm{CO}_{2}$ showed the decomposition of solvents(EC and DEC) occurred by deposited lithium and the surface of deposited lithium was active for the reduction of solvents in $\mathrm{EC}+\mathrm{DEC}$.

Figure 7 compares DMFTIR spectra of $1 \mathrm{~mol} / \mathrm{dm}^{3}$ $\mathrm{LiPF}_{6} / \mathrm{EC}+\mathrm{DMC}$ at $\mathrm{OCV}$ (around $3 \mathrm{~V}$ ) and after deposition. The subtractive spectrum $(7 \mathrm{c})$ shows the difference between the spectrum at $\operatorname{OCV}(7 \mathrm{a})$ and after deposition (7b). The major increasing peak was observed at 1679 $\mathrm{cm}^{-1}\left(v_{\mathrm{C}=0}\right)$, with other peaks at 1123,1012, 933 and $803 \mathrm{~cm}^{-1}$. Aurbach reported that the IR spectra of lithium alkylcarbonates $\left(\mathrm{ROCO}_{2} \mathrm{Li}\right)$ have their peaks around $1650\left(\mathrm{UC}_{\mathrm{C}}=\mathrm{O}\right.$, as $), 1450$ to $1400\left(\delta_{\mathrm{CH}_{2}}\right), 1350$ to 1290 $(v \mathrm{c}=0, \mathrm{~s}),$.1100 to $1070(\mathrm{vc}-\mathrm{o})$, and 840 to $820 \mathrm{~cm}^{-1}$ $\left(\delta_{\mathrm{OCO}_{2}}\right)^{3,4)}$ But, the observed peaks at $1679\left(\mathrm{vC}_{\mathrm{C}} \mathrm{o}\right)$ and $1123 \mathrm{~cm}^{-1}\left(v_{\mathrm{c}-0}\right)$ were shifted about $30 \mathrm{~cm}^{-1}$ from those of reported, and the other peaks at $1012\left(\mathrm{vc}_{-} \mathrm{O}\right), 933$ and $803 \mathrm{~cm}^{-1}$ were not consistent with the peaks of $\mathrm{ROCO}_{2} \mathrm{Li}$. Therefore we think that the peaks at $1679\left(\mathrm{u}_{\mathrm{C}=\mathrm{O}}\right)$ and $1123 \mathrm{~cm}^{-1}$ (uc-o) will be ascribed to lithium alkylcarbonate

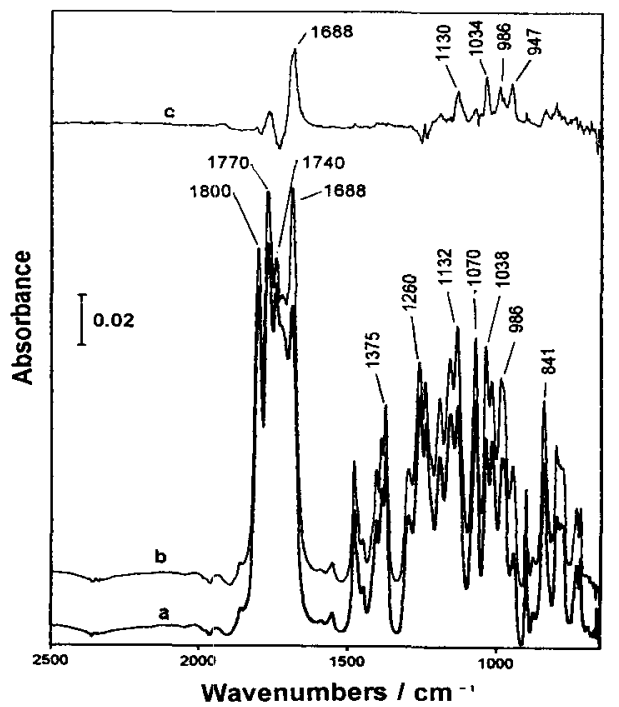

Fig. 8 Comparison of DMFTIR spectra of LiPF $6 / E C+$ DEC at OCV and after deposition. a; OCV(around 3V), b; after deposition, c; subtractive spectrum. 
Table 1 Summary of the wave analysis for the peaks of $C=0$ stretching vibration in DMFTIR spectra of $7 b\left(L_{i P F} / E C+D M C\right)$ and $8 b\left(L i P F{ }_{6} / E C+D E C\right)$.

\begin{tabular}{|c|c|c|c|c|c|c|c|c|c|}
\hline No. & $\begin{array}{l}\text { Center of peak } \\
\text { (cm }{ }^{-1} \text {,assignmen }\end{array}$ & $\begin{array}{l}\text { Height } \\
\text { (t) }\end{array}$ & Area & $\begin{array}{l}\text { Share } \\
(\%)\end{array}$ & No. & $\begin{array}{l}\text { Center of peak } \\
\left(\mathrm{cm}^{-1} \text {, assignmer }\right.\end{array}$ & $\begin{array}{l}\text { Height } \\
\text { nt) }\end{array}$ & Area & $\begin{array}{l}\text { Share } \\
(\%)\end{array}$ \\
\hline \multicolumn{3}{|c|}{ LiPF $6 / E C+D M C$} & \multicolumn{7}{|c|}{ LiPF 。/EC+DEC } \\
\hline $7-1$ & $1802(E C)$ & 0.109 & 2.814 & 22.6 & 8-1 & $1801(E C)$ & 0.117 & 3.302 & 20.9 \\
\hline \multirow[t]{2}{*}{$7-2$} & $1772(E C)$ & 0.103 & 1.858 & 14.9 & $8-2$ & 1773 (EC) & 0.095 & 1.483 & 9.4 \\
\hline & & & & & $8-3$ & 1761 (product) & 0.104 & 2.091 & 13.2 \\
\hline $7-3$ & $1750(\mathrm{DMC})$ & 0.142 & 3.731 & 30.0 & $8-4$ & 1741(DEC) & 0.101 & 2.138 & 13.5 \\
\hline $7-4$ & 1724(product) & 0.073 & 1.669 & 13.4 & 8-5 & 1722(product) & 0.083 & 1.810 & 11.4 \\
\hline $7-5$ & 1710 (product) & 0.010 & 0.119 & 1.0 & $8-6$ & 1709 (product) & 0.036 & 0.564 & 3.6 \\
\hline $7-6$ & 1687 (product) & 0.071 & 2.260 & 18.1 & 8-7 & 1687 (product) & 0.114 & 4.431 & 28.0 \\
\hline
\end{tabular}

or ester-compound, and the other peaks observed from 1012 to $803 \mathrm{~cm}^{-1}$ will be ascribed to ether-compounds. The peak of $\mathrm{Li}_{2} \mathrm{CO}_{3}$ was not clearly observed at the spectrum $7 \mathrm{~b}$, although this peak was observed at around $880 \mathrm{~cm}^{-1}$ $\left(\delta_{\mathrm{OCO}_{2}}\right)$ in the DMFTIR spectra of the lithium surface.

A comparison of DMFTIR spectra of $1 \mathrm{~mol} / \mathrm{dm}^{3} \mathrm{LiPF}_{6} /$ $\mathrm{EC}+\mathrm{DEC}$, as the same in Fig. 7, is shown in Fig. 8. The major increased peak in the subtractive spectrum(8c) was observed at $1688 \mathrm{~cm}^{-1}(\mathrm{UC}=0)$, with other peaks at 1130 , 1034,986 and $947 \mathrm{~cm}^{-1}$. This spectrum $8 \mathrm{c}$ was similar to the spectrum at the reduction of electrolytes as reported in our previous paper. ${ }^{10)}$ The peaks at $1688 \mathrm{~cm}^{-1}(\mathrm{UC}=0)$ and $1130 \mathrm{~cm}^{-1}$ (Uc-o) will be ascribed to lithium alkylcarbonate, and the other peaks observed from 1130 to $947 \mathrm{~cm}^{-1}$ will be ascribed to ether-compounds.

We think that the difference in the interfacial reactions of electrolytes effected on the surface chemistry of electrodes and the morphology of deposited lithium. The wave analysis of the peaks in DMFTIR spectra was conducted to analyze the interfacial reaction in detail, since the DMFTIR spectra could indicate the changes of species at the interface. The wave analysis was performed for the dominant peaks from 1850 to $1600 \mathrm{~cm}^{-1}$, due to $\mathrm{C}=\mathrm{O}$ stretching vibration of lithium alkylcarbonates and ester-compounds, in the DMFTIR spectra of $7 b$ and $8 b$, using the curve fitting program in GRAMS/386 software (Galactic). The result of the curve fitting of the spectrum $8 \mathrm{~b}$ is shown in Fig. 9 and the summary of results are shown in Table 1. The peaks due to $\mathrm{C}=\mathrm{O}$ stretching vibration of $8 \mathrm{~b}$ was divided 7 peaks as shown $8-1 \sim 7$ in Fig.9. The characteristic peak of $8-3$ was appeared at $1761 \mathrm{~cm}^{-1}$ and this peak would be ascribed to reduction product of DEC. The results of the curve fitting of the spectra $7 \mathrm{~b}$ and $8 \mathrm{~b}$ showed similar peak patterns except of the peak of 8-3. Since the peaks of $7-1\left(1802 \mathrm{~cm}^{-1}\right)$ and $7-$ $2\left(1772 \mathrm{~cm}^{-1}\right)$ were consistent with the peaks of 8 $1\left(1801 \mathrm{~cm}^{-1}\right)$ and $8-2\left(1772 \mathrm{~cm}^{-1}\right)$, they were assigned to EC The peaks of $7-3\left(1750 \mathrm{~cm}^{-1}\right)$ and $8-4\left(1741 \mathrm{~cm}^{-1}\right)$ were

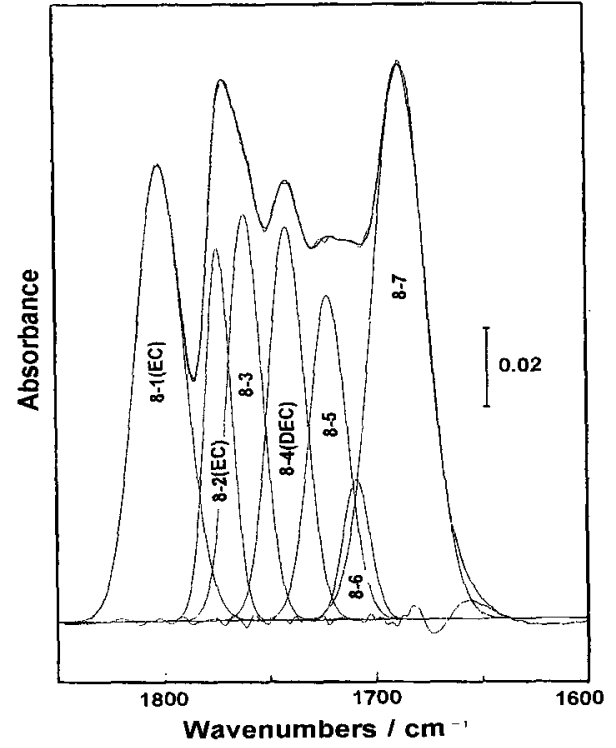

Fig. 9 Results of curve fitting for DMFTIR spectrum of after deposition(8b) in LiPF 6 EC+DEC. center of peak; 8-1: 1801, 8-2: 1773, 8-3: 1761, 8-4: 1741, 8-6: 1722, 8-6: $1709,8-7: 1687 \mathrm{~cm}^{-1}$.

assigned to DMC and DEC, respectively. In addition, the peaks of 7-6 and 8-7 were ascribed to the decomposition product of EC, since they were appeared at the same wave number $\left(1687 \mathrm{~cm}^{-1}\right)$. The other peaks would be ascribed to reduction products of DMC and DEC, respectively. We thought that the ratio of species existing at the interface was influenced the ratio of products. Indeed, in EC+DMC system, the ratio of EC to DMC was 10 to 8 , and the ratio of product of $\mathrm{EC}(7-6)$ to those of $\operatorname{DMC}(7-4,5)$ was also 10 to 8 . On the other hand, the ratio of EC to DEC was $10: 4$, but the ratio of products was $10: 10$ in EC+DEC system. This result indicated the amount of reduction products of solvents, which were insoluble, were much more than those in EC+DMC. In addition, the ratio of solvents to products was $2: 1$ in $E C+D M C$, but this ratio was $2: 3$ in EC+DEC. It was clearly shown in Fig. 8 that 
the peak at $1688 \mathrm{~cm}^{-1}(\mathrm{vc}=0)$ due to reduction product of EC was the major increasing peak after deposition in $\mathrm{EC}+\mathrm{DEC}$. These results indicated that reduction products of DEC proceeded much more than in EC+DMC system, and the coexistence with reduction products of $\mathrm{DEC}$ at the interface increased the decomposition of EC. A comparison of IRAS spectra after lithium deposition between in EC+DMC(Fig.5) and in EC+DEC(Fig.6) showed the major dissoluble reduction product was ethercompound in the both electrolytes. Therefore the difference in lithium deposition was caused by the behavior of insoluble reduction products of solvents. From these results, we think that since reduction products of DEC were insufficient for the passivation of the electrode surface and the passivation was accomplished by only reduction products of $\mathrm{EC}$, the amount of reduction products of solvents was much higher in $\mathrm{EC}+\mathrm{DEC}$ than in EC+DMC. Since the most part of the surface of electrode were covered with particles of these products (as shown in Fig.4d), lithium deposited on uncoverd parts of the surface. Therefore the nuclei of lithium deposition were partially formed on the surface, and the morphology of deposition was observed as a formation of larger particles in $\mathrm{EC}+\mathrm{DEC}$ than those in $\mathrm{EC}+\mathrm{DMC}$.

Consequently, our results in this DMFTIR spectroscopy prove that the assumption for the stability of lithium and carbon electrodes in EC+DEC solution by Aurbach ${ }^{3,4)}$ is correct. We think that the differences between in $\mathrm{LiPF}_{6} / \mathrm{EC}+\mathrm{DMC}$ and in $\mathrm{LiPF}_{6} / \mathrm{EC}+\mathrm{DEC}$ are following points,

1) the amount of insoluble reduction products in EC+DEC, which were precipitated on the electrode surface, was much higher than that of in EC+DMC, but the surface of deposited lithium was insufficient for the passivation.

2) the characteristic reduced product $\left(u \mathrm{C}-0 ; 1761 \mathrm{~cm}^{-1}\right)$ of DEC was observed at the electrode surface in EC+DEC.

3) the morphological changes of the surface due to the reduction of solvents were observed as a formation of relatively large particles(around $500 \mathrm{~nm}$ in size) in $\mathrm{EC}+\mathrm{DEC}$.

4) the growth of lithium deposited on $\mathrm{Cu}$ electrode was observed as a formation of large particles(around $1000 \mathrm{~nm}$ in size) in EC+DEC, on the other hand, the gatherings of small particles(around $400 \mathrm{~nm}$ in size) were observed in $\mathrm{EC}+\mathrm{DMC}$, at $1 \mathrm{~mA} / \mathrm{cm}^{2}$.

\section{CONCLUSION}

This study proved that AFM observation and FTIR spectroscopy were the effective analysis for the interfacial reactions between electrode and organic electrolytes. The morphology of electrodeposited lithium at $\mathrm{Cu}$ electrodes were observed as a formation of small particles with $300 \sim 600 \mathrm{~nm}$ in size at the first stage of deposition. As the deposition was proceeded, some gatherings of small particles were observed and these lamps seemed to grow as the nuclei of the dendritic growth. It was found in this study that the current density of deposition effects on this secondary growth.

The effects of solvents were appeared as the particles size of deposited lithium and the growth mechanism of deposition. The in situ FTIR spectroscopy, especially DMFTIR method, proved the difference in the interfacial reaction(the reduction of solvents) at $\mathrm{Cu}$ electrodes. In both electrolyte solutions $\left(\mathrm{LiPF}_{6} / \mathrm{EC}+\mathrm{DMC}\right.$ and $\mathrm{LiPF}_{6} /$ $\mathrm{EC}+\mathrm{DEC}$ ), solvents were reduced into insoluble products (lithium alkylcarbonates) and dissoluble products(ethercompounds). The amount of insoluble products in EC+DEC system was much higher than that of in $\mathrm{EC}+\mathrm{DMC}$ system, and the accumulation or adsorption of these products obstructed the deposition and growth of lithium.

The authors express their sincere thanks to the New Energy and Industrial Technology Development Organization for their support of this work.

\section{REFERENCES}

1) D. Aurbach, M.L. Daroux, P.W. Faguy and E. Yeager, J. Electrochem. Soc., 134, 1611 (1987)

2) D. Aurbach, A. Zaban, Y. Gofer, Y. Ein-Eli, I Weissman, $\mathrm{O}$. Chusid and $\mathrm{O}$. Abramson, J. Power Sources, 54, 76 (1995).

3) D. Aurbach, A. Zaban, A. Shechter, Y. Ein-Eli, E Zinigrad and B. Markovsky, J. Electrochem. Soc., 142, 2873, (1995).

4) D. Aurbach, B.Markovsky, A. Shechter, Y. Ein-Eli and H. Cohen, J. Electrochem. Soc., 143, 3809, (1996).

5) K. Morigaki, N. Kabuto, K. Yoshino and A. Ohta, 35th Battery Symposium of Japan, Extended Abstracts, 83, (1994).

6) K. Morigaki, N. Kabuto, K. Yoshino and A. Ohta, Power Sources 15 (Eds. A.Attewell and T.Keily), Int Power Sources Symposium Committee, 267, (1995).

7) D. Aurbach and Y. Cohen, J. Electrochem. Soc., 143, 3525, (1996).

8) M. Tatsumi, FTIR no Kiso to Jissai (2nd.Ed.). Tokyo kagaku doujin, Tokyo, p112, (1994)

9) W N. Richmond, P.W. Faguy, R.S. Jackson and S.C. Weibel, Anal. Chem., 68, 621, (1996).

10) K. Morigaki, T. Fujii and A. Ohta, Denki Kagaku, previous report. 